\title{
Associations of fruit \& vegetable intake and physical activity with poor self-rated health among Chinese older adults
}

Ming Guan ${ }^{1,2,3 *}$

\begin{abstract}
Background: Despite the existing literature highlights the central roles of sociodemographic factors, fruit \& vegetable (F\&V) intake, and physical activities for maintaining good health, less is known about the associations in the Chinese context. This study attempted to explore the associations of servings of F\&V intake and levels of physical activities with poor self-rated health (SRH) among Chinese older adults.

Methods: Data were drawn from the Study on Global Ageing and Adult Health-China (SAGE-China) issued by the World Health Organization and included 7560 respondents aged $\geq 60$ years in China. After screening out the potential confounding factors, multiple logistic regression models were adopted to explore the associations of sociodemographic factors, servings of F\&V intake, and levels of physical activities with poor SRH.

Results: Among the sample, nearly a quarter reported poor health status. There were significant gender differences in the case of servings of F\&V intake and levels of physical activities. Logistic regressions indicated that higher fruit intake was associated with lower likelihood of vigorous level of physical activity as compared to zero intake. Likewise, higher vegetable intake ( $\geq 10$ servings) was associated with a higher likelihood of vigorous \& moderate level of physical activity when compared to lower intake ( $\leq 4$ servings). Higher fruit intake was associated with a lower likelihood of poor SRH. Similarly, vegetable intake ( 5 servings: $\mathrm{AOR}=0.69,95 \% \mathrm{Cl}: 0.58-0.83 ; 6-9$ servings: $\mathrm{AOR}=0.72,95 \% \mathrm{Cl}$ : $0.59-0.87$ ) was significantly associated with poor SRH. Additionally, vigorous level of physical activity $(A O R=0.79$, $95 \% \mathrm{Cl}: 0.65-0.97)$ and vigorous fitness/leisure (AOR $=0.57,95 \% \mathrm{Cl}: 0.39-0.84)$ were significantly associated with poor $\mathrm{SRH}$.

Conclusion: This study suggested that older adults with high fruit intake had lower probability of performing vigorous \& moderate level of physical activity, while those with high vegetable intake had higher probability of performing vigorous \& moderate level of physical activity. Likewise, the older adults with high F\&V intake and higher probability of performing vigorous level of physical activity, walk/bike activity, and vigorous/moderate fitness/leisure had less likelihood to face the risk for poor SRH outcomes. The appropriate servings of F\&V intake and levels of physical activity should be highlighted.
\end{abstract}

Keywords: Chinese older adults, Servings of F\&V intake, Levels of physical activity, Poor SRH, Sociodemographic factors

*Correspondence: gming0604@163.com

${ }^{3}$ School of Business, Xuchang University, Road Bayi 88, Xuchang, Henan, China

Full list of author information is available at the end of the article

\section{Background}

There is an increased attention towards health status among the older adults in China. Many studies research found there was high prevalence of normal-weight 
obesity [1], cognitive impairment [2], anaemia [3], and reduced kidney function [4] among Chinese older adults. Likewise, a meta-analysis indicated estimated proportions of sleep duration $<5 \mathrm{~h} /$ day and $<6 \mathrm{~h} /$ day were $18.8 \%$ (95\% CI: $1.7-35.9 \%$ ) and $26.7 \%$ (95\% CI: $19.7-33.7 \%$ ) in Chinese older adult population, respectively [5]. Additionally, Chinese older adults demonstrated high incidences of physical inactivity (62.5\%) and unhealthy dietary behavior (45.7\%) [6]. Similarly, a study reported Chinese older adults aged $>70$ years performed physical activities quite frequently with low and medium intensity for a short time period [7]. Moreover, a high proportion (27.71\%) of older adults with poor SRH was confirmed in the Chinese individuals aged $\geq 60$ years [8].

Since entry into the ageing society, the associated factors of general health status among Chinese older adults have attracted academic attention [9]. In China, SRH was consistent with objective health status and could serve as a global measure of health status in the general population [10]. SRH could directly predict the subjective well-being [11] and be reflected by income inequality among Chinese older adults [12]. China had some differences from other countries regarding how sociodemographic factors and behaviors influenced SRH [13-16]. Likewise, an empirical outcome indicated that associations between socioeconomic disadvantages and health changes in China were possibly similar to those found in western populations [17]. These prior studies collectively suggested that a similar research on the associations regarding SRH in the field of Chinese geriatric research was needed.

Prior research confirmed that sociodemographic factors contributed to servings of F\&V intake, levels of physical activities, and poor SRH in western countries. For example, economic level and social characteristics were associated with low F\&V intake within the deprived French population [18]. Simultaneously, a study reported that educational level was correlated to levels of physical activities [19]. Another study indicated that the correlations of physical activities with sociodemographic and health factors differed significantly from levels of physical activities [20]. Likewise, education [21], income [22], area factors [23], marital status [24], occupations [25], and living arrangements [26] were reported to be associated with SRH. Thus, when assessing the associations of servings of F\&V intake and levels of physical activities with poor SRH, sociodemographic factors could possibly be the potential confounding factors.

There were several theories regarding the relationship between physical activities and health promotion, including health behavior theories [27], theory of planned behavior [28], multi-theory model of health behavior change [29], and health belief model [30].
The core proposition of those theories was that physical activities could promote health status among various population groups. However, scarce theoretical relationship between diet and health promotion was reported. Particularly, normalization process theory was proved to be useful in conceptualizing barriers to implementation of the nutrition guidelines for older people [31]. Additionally, theory of planned behavior was employed to predict physical activities and $F \& V$ intake of young rather than older population [32]. Here, the theories above were adopted as theoretical foundation and analytical framework for analyzing the associations of $F \& V$ intake and physical activities with poor SRH.

The relationship between servings of F\&V intake and levels of physical activities was documented in the western world. For instance, a cross-sectional study in the Netherlands concluded physically active older adults tended to consume more $\mathrm{F} \& \mathrm{~V}$ compared to less active peers [33]. Another cross-sectional study among 810 adults aged $\geq 85$ years indicated that high levels of physical activity could be achieved by improving overall diet [34]. Based on prior research, this study could hypothesize below,

Hypothesis 1: Controlling for potentially confounding factors, lower fruit intake has significantly negative association with higher levels of physical activities in Chinese older adults.

Hypothesis 2: Controlling for potentially confounding factors, lower vegetable intake has significantly negative association with higher levels of physical activities in Chinese older adults.

Simultaneously, the association of servings of F\&V intake with SRH has been well documented in western countries. For example, two studies in UK and Portugal showed that servings of F\&V intake were associated with SRH $[35,36]$. Clinically, F\&V intake could improve health status of patients [37-39]. Specifically, research has shown appropriate servings of F\&V intake could prevent cognitive dysfunction [40], mental disorders [41], and cardiovascular disease [42]. Thus, the following hypotheses were posited:

Hypothesis 3: Controlling for potentially confounding factors, lower fruit intake has significantly positive association with poor SRH in Chinese older adults.

Hypothesis 4: Controlling for potentially confounding factors, lower vegetable intake has significantly positive association with poor SRH in Chinese older adults. 
Furthermore, it was confirmed scientific intensity of physical activity could benefit and improve physical and mental health $[43,44]$. Likewise, a cross-sectional study reported long working hours were associated with increased risk of poor SRH [45]. Also, a cross-sectional study highlighted the potential for promotion of physical activity to reduce socioeconomic inequalities in SRH [46]. In a similar vein, several prior studies demonstrated that good SRH was supported by physical activities in adults [47-49] and adolescents [50-53]. Additionally, a review revealed the mechanisms of physical activity causing clinical changes in health status [54]. Based on previous research, the following hypothesis was given:

Hypothesis 5: Controlling for potentially confounding factors, higher levels of physical activities have significantly negative association with poor SRH in Chinese older adults.

\section{Method}

Data

The publically available dataset regarding the health and physical activities of older populations in China, titled the Study on Global Ageing and Adult Health-China (SAGE-China), was used in this study. The SAGE-China survey with a multistage stratified cluster sample design was completed as a face-to-face household survey in China in 2010. In SAGE-China, there were 95\% response rate for the household questionnaire and $>98 \%$ response rate for the individual questionnaire. After excluding the 7449 persons aged $<60$ years and 41 missing values, 7560 Chinese older adults aged $\geq 60$ years were obtained from the dataset.

\section{Main variables}

\section{Dependent variables}

The dependent variables were poor SRH and physical activities. SRH was assessed by the question: "In general, how would you rate your health today?" with five-point Likert scales ranging from" $1=$ very good" to " $5=$ very bad". Thus, poor SRH was obtained by dichotomizing the response options into binary values: 1 (poor $=\mathrm{bad} /$ very bad) and 0 (good=very good/good/so so). Physical activities (time $\geq 10 \mathrm{~min}$ ) mainly included moderate level of physical activity, vigorous level of physical activity, walk/bike activity, moderate fitness/leisure, and vigorous fitness/leisure. The response options of physical activities were yes $(=1)$ and no $(=0)$.

\section{Independent variables}

The main independent variables were physical activities, fruit intake, and vegetable intake. Fruit intake was measured by the question: "How many servings of fruit do you eat on a typical day?" Respondents reported the number of servings they consumed banana, mango, apple, orange, papaya, tangerine, grapefruit, peach, and pear. Vegetable intake was measured by the question: "How many servings of vegetables do you eat on a typical day?" Respondents reported the number of servings they consumed tomatoes, cauliflowers, potatoes, cucumbers, peas, corns, lettuces, squashes, and beans. With respect to statistical density, respondents' servings of fruit and vegetable intake were divided by $0,1,2,3$, and $\geq 4$ and $0-4,5,6-9$, 10 , and $\geq 11$, respectively.

\section{Sociodemographic factors}

The sociodemographic variables included age, gender, marital status, ever schooled, ethnicity, and always lived in this village/town/city. Age was divided into two groups: 60 to 69 years and 70 years and above. Gender was categorized as female $(=0)$ and male $(=1)$. Marital status was categorized as never married, currently married, cohabited, separated/divorced, and widowed status. Ever schooled level was divided by no $(=0)$ and yes $(=1)$. Ethnicity was grouped by Han majority $(=0)$ and ethnic minority $(=1)$. The response options of "always lived in this village/town/city" were classified into no $(=0)$ and yes $(=1)$.

\section{Statistical analyses}

First, descriptive statistics were carried out by Chisquare tests with percentages to reflect the sample characteristics. Second, principal component analysis (PCA) with varimax rotation and method of maximum likelihood was performed regarding the factor analysis of physical activities. In PCA, components with an eigenvalues $>1$ were retained. In the exploratory factor analysis, component loadings $<0.5$ were deleted. PCA was conducted by SPSS 22.0. Regarding convergent validity and discriminant validity assessment, squared correlations among latent variables and average variances extracted (AVEs) were calculated with Stata program "condisc" [55]. According to Fornell and Larcker (1981), AVE values less than 0.5 was rejected [56]. Consequently, the five domains of physical activities could separately conduct as dependent variables.

On the basis of change-in-estimate criterion $(>0.09 \%$ cutoff) [57] in a stepwise fashion, the next step was to identify potential confounding factors with Stata program "confnd" [58] in the associations between servings of fruit intake and levels of physical activities, between servings of vegetable intake and levels of physical activities, between servings of F\&V intake and poor SRH, and between levels of physical activities and poor SRH. After screening out the potential confounding factors, multiple logistic regression models of interest were conducted 
to explore the associations of interest among servings of fruit intake, servings of vegetable intake, levels of physical activities, and poor SRH. Here, risks were expressed as adjusted odds ratio (AOR) with $95 \%$ confidence interval (CI).

The main statistical analyses were performed using Stata version 14.0.

\section{Results}

In Table 1, mean age of the sample was 69.79 (Standard deviation $=7.10$, range $=60$ to 99 ) years old. $24.50 \%$ of respondents reported poor health status. There were not significant gender differences in age groups. Regarding gender, number of females (52.62\%) was somewhat more than number of males (47.38\%). Considering marital status, there were significant gender differences among never married, currently married, cohabited, separated/ divorced, and widowed status. The top two patterns of marital status were currently married $(75.48 \%)$ and widowed status (22.07\%), which accounted for $97.55 \%$ of the total sample. Most of the sample was educated (65.77\%) and belonged to Han majority (98.66\%). The number of older adults always lived in this village/town/city and that not always lived in this village/town/city was nearly equal to each other, while the number of older adults not always lived in this village/town/city were somewhat more (50.62\%). Women had higher F\&V intake than men. There were significant gender differences in the case of vigorous level of physical activity, moderate level of physical activity, walk/bike activity, vigorous fitness/leisure, and moderate fitness/leisure. Most of the respondents did not perform vigorous level of physical activity, vigorous fitness/leisure, or moderate fitness/leisure. Over half of them did perform not moderate level of physical activity but walk/bike activity. There were high proportions of fruit intake ( $\geq 2$ servings), vegetable intake ( $\geq 5$ servings), moderate level of physical activity, walk/bike activity, and moderate fitness/leisure.

Regarding factor analysis of levels of physical activities, the statistical outcomes indicated adequate sample size and significant Bartlett's test of sphericity (Kaiser-MeyerOlkin adequacy $=0.555$ and Bartlett's sphericity test: Chisquare $(10)=1494.894, p<0.001)$. This analysis allowed to identify two factors with eigenvalue (Kaiser's criterion) greater than 1 (1.485 and 1.167), conjointly accounting for $53.053 \%$ of the total variance. The two factor solution could be named work activity (items: vigorous level of physical activity and moderate level of physical activity) and leisure activity (items: walk/bike activity, vigorous fitness/leisure, and moderate fitness/leisure), respectively. Their Cronbach's alpha coefficients were 0.4198 (Factor 1) and 0.2279 (Factor 2), respectively. Likewise, squared correlation between work activity and leisure activity was
0.214 . AVEs were 0.341 and 0.197 in the latent variables of work activity and leisure activity, respectively. Thus, structural equation modeling was abandoned and logistic regression could be adopted.

\section{Association between servings of fruit intake and levels of physical activities}

Supplementary Table 1a to e reported change-in-estimates for vigorous level of physical activity, moderate level of physical activity, walk/bike activity, vigorous fitness/leisure, and moderate fitness/leisure to fruit intake with the potential confounding factors. In Table 2, higher fruit intake was associated with lower odds of performing vigorous level of physical activity. Additionally, fruit intake ( 1 serving: $\mathrm{AOR}=0.81,95 \% \mathrm{CI}$ : $0.68-0.96$; $\geq 4$ servings: $\mathrm{AOR}=0.83,95 \% \mathrm{CI}: 0.73-0.95)$ was associated with a lower likelihood of performing physical activity at a moderate level. Similarly, fruit intake $\geq 1$ serving was associated with a higher likelihood of performing walk/ bike activity. Moreover, higher fruit intake was associated with a lower likelihood of performing vigorous fitness and leisure activities. Additionally, higher fruit intake was associated with lower odds of performing moderate fitness and leisure activities. Accordingly, Hypothesis 1 was not confirmed partially.

\section{Association between servings of vegetable intake and levels of physical activities}

Supplementary Table 2a to e reported change-in-estimates for vigorous level of physical activity, moderate level of physical activity, walk/bike activity, vigorous fitness/leisure, and moderate fitness/leisure to vegetable intake with the potential confounding factors. In Table 3, older adults with 10 servings and $\geq 11$ servings of vegetable intake had $67 \%$ ( 10 servings: $\mathrm{AOR}=1.67,95 \% \mathrm{CI}$ : $1.30-2.13)$ and $275 \%(\geq 11$ servings: $\mathrm{AOR}=3.75,95 \% \mathrm{CI}$ : 2.89-4.87) higher probabilities of performing vigorous level of physical activity than those without it. Older adults with high vegetable intake ( $\geq 10$ servings) would more likely to perform moderate level of physical activity. Older adults with high vegetable intake ( $\geq 5$ servings) and fruit intake ( $\geq 1$ serving) would have higher probability of performing walk/bike activity. The significantly negative association between vigorous fitness/leisure and vegetable intake was confirmed. Furthermore, the significantly negative association between moderate fitness/leisure and vegetable intake was observed. Therefore, Hypothesis 2 was not confirmed completely.

Association between servings of $F \& V$ intake and poor SRH Supplementary Table $3 \mathrm{a}$ and b reported change-inestimates for poor SRH to $F \& V$ intake with potential confounding factors. In Table 4 , high fruit intake $(\geq 1$ 
Table 1 Descriptive characteristics stratified by gender among the 7560 respondents (\%)

\begin{tabular}{|c|c|c|c|c|c|}
\hline Variables & Total & Men & Women & Chi-square & $P$-value \\
\hline Poor SRH & & & & 29.2419 & $0.000^{* * *}$ \\
\hline No & 75.50 & 37.13 & 38.37 & & \\
\hline Yes & 24.50 & 10.25 & 14.25 & & \\
\hline Age group (years) & & & & 0.1656 & 0.684 \\
\hline $60-69$ & 52.49 & 25.01 & 27.47 & & \\
\hline$\geq 70$ & 47.51 & 22.42 & 25.09 & & \\
\hline Marital status & & & & 440.5079 & $0.000^{* * *}$ \\
\hline Never married & 0.90 & 0.53 & 0.37 & & \\
\hline Currently married & 75.48 & 40.68 & 34.80 & & \\
\hline Cohabited & 0.17 & 0.08 & 0.09 & & \\
\hline Separated/Divorced & 1.38 & 0.68 & 0.70 & & \\
\hline Widowed & 22.07 & 5.48 & 16.59 & & \\
\hline Ever schooled & & & & 537.4515 & $0.000^{* * *}$ \\
\hline Yes & 65.77 & 37.51 & 28.25 & & \\
\hline No & 34.23 & 9.92 & 24.31 & & \\
\hline Ethnicity & & & & 1.2821 & 0.258 \\
\hline Han majority & 98.66 & 46.68 & 51.98 & & \\
\hline Ethnic minority & 1.34 & 0.71 & 0.63 & & \\
\hline Always lived in this village/town/city & & & & 292.5727 & $0.000^{* * *}$ \\
\hline Yes & 49.38 & 28.45 & 20.93 & & \\
\hline No & 50.62 & 19.02 & 31.59 & & \\
\hline Fruit intake & & & & 17.7284 & $0.001^{* * *}$ \\
\hline 0 & 23.41 & 12.17 & 11.24 & & \\
\hline 1 & 13.21 & 6.14 & 7.06 & & \\
\hline 2 & 26.44 & 12.42 & 14.02 & & \\
\hline 3 & 14.02 & 6.23 & 7.79 & & \\
\hline$\geq 4$ & 22.92 & 10.66 & 12.26 & & \\
\hline Vegetable intake & & & & 44.4884 & $0.000^{* * *}$ \\
\hline $0-4$ & 27.93 & 11.86 & 16.07 & & \\
\hline 5 & 24.64 & 11.47 & 13.17 & & \\
\hline $6-9$ & 19.41 & 9.49 & 9.92 & & \\
\hline 10 & 19.61 & 9.92 & 9.68 & & \\
\hline$\geq 11$ & 8.41 & 4.71 & 3.70 & & \\
\hline Vigorous level of physical activity & & & & 129.0088 & $0.000^{* * *}$ \\
\hline Yes & 11.71 & 7.68 & 4.03 & & \\
\hline No & 88.29 & 39.66 & 48.63 & & \\
\hline Moderate level of physical activity & & & & 3.3725 & $0.066^{*}$ \\
\hline Yes & 45.17 & 20.87 & 24.30 & & \\
\hline No & 54.83 & 26.51 & 28.31 & & \\
\hline Walk/bike activity & & & & 15.4592 & $0.000^{* * *}$ \\
\hline Yes & 66.50 & 32.56 & 33.94 & & \\
\hline No & 33.50 & 14.77 & 18.73 & & \\
\hline Vigorous fitness/leisure & & & & 19.5856 & $0.000^{* * *}$ \\
\hline Yes & 4.08 & 2.45 & 1.64 & & \\
\hline No & 95.92 & 44.93 & 50.99 & & \\
\hline Moderate fitness/leisure & & & & 8.7883 & $0.003^{* * *}$ \\
\hline Yes & 15.77 & 8.10 & 7.67 & & \\
\hline No & 84.23 & 39.24 & 44.99 & & \\
\hline
\end{tabular}

Note: ***** and *indicates 1,5 and $10 \%$ significance level, respectively 
Table 2 Adjusted odds ratios (and 95\% confidence intervals) of fruit intake (servings) and physical activities, AOR(95\%Cl)

\begin{tabular}{|c|c|c|c|c|c|}
\hline & $\begin{array}{l}\text { Vigorous level of } \\
\text { physical activity }\end{array}$ & $\begin{array}{l}\text { Moderate level of } \\
\text { physical activity }\end{array}$ & Walk/bike activityc & Vigorous fitness/leisure $^{d}$ & Moderate fitness/leisure \\
\hline \multicolumn{6}{|l|}{ Fruit intake } \\
\hline 0 & 1 [Reference] & 1 [Reference] & 1 [Reference] & 1 [Reference] & 1 [Reference] \\
\hline 1 & $0.40^{* * *}(0.29-0.55)$ & $0.81^{* *}(0.68-0.96)$ & $1.24^{* *}(1.01-1.52)$ & $0.05^{* * *}(0.04-0.08)$ & $0.25^{* * *}(0.20-0.30)$ \\
\hline 2 & $0.52^{* * *}(0.42-0.65)$ & $1.08(0.95-1.22)$ & $1.38^{* * *}(1.17-1.63)$ & $0.05^{* * *}(0.04-0.06)$ & $0.29^{* * *}(0.26-0.34)$ \\
\hline 3 & $0.41^{* * *}(0.31-0.56)$ & $1.10(0.93-1.30)$ & $1.31^{* *}(1.07-1.60)$ & $0.04^{* * *}(0.03-0.06)$ & $0.36^{* * *}(0.31-0.42)$ \\
\hline$\geq 4$ & $0.39^{* * *}(0.31-0.50)$ & $0.83^{* * *}(0.73-0.95)$ & $1.32^{* * *}(1.12-1.57)$ & $0.06^{* * *}(0.04-0.07)$ & $0.39^{* * *}(0.34-0.44)$ \\
\hline \multicolumn{6}{|l|}{ Age group (years) } \\
\hline $60-69$ & & & & & 1 [Reference] \\
\hline$\geq 70$ & & & & & $0.42^{* * *}(0.38-0.47)$ \\
\hline \multicolumn{6}{|l|}{ Marital status } \\
\hline Never married & 1 [Reference] & & 1 [Reference] & & \\
\hline Currently married & $0.32^{* * *}(0.28-0.38)$ & & $1.78^{* * *}(1.57-2.01)$ & & \\
\hline Cohabiting & $0.44(0.09-2.10)$ & & $1.56(0.40-6.09)$ & & \\
\hline Separated/divorced & $0.19^{* * *}(0.09-0.38)$ & & $2.44^{* * *(1.48-4.04)}$ & & \\
\hline Widowed & $0.18^{* * *}(0.14-0.22)$ & & $1.38^{* * *(1.18-1.61)}$ & & \\
\hline \multicolumn{6}{|l|}{ Ethnicity } \\
\hline Han majority & 1 [Reference] & & 1 [Reference] & 1 [Reference] & 1 [Reference] \\
\hline Ethnic minority & $0.47^{*}(0.22-1.01)$ & & $0.72(0.43-1.21)$ & $0.10^{* * *}(0.03-0.35)$ & $0.47^{* *}(0.25-0.90)$ \\
\hline \multicolumn{6}{|c|}{ Always lived in this village/town/city } \\
\hline Yes & & 1 [Reference] & & & \\
\hline No & & 0.96(0.86-1.07) & & & \\
\hline \multicolumn{6}{|c|}{ Note: ***,** and ${ }^{*}$ indicates 1,5 and $10 \%$ significance level, respectively } \\
\hline \multicolumn{6}{|c|}{ AOR adjusted odds ratio } \\
\hline \multicolumn{6}{|c|}{ a Age group, gender, ever schooled, always lived in this village/town/city, vegetable intake, and poor SRH were screened out as the confounding variables } \\
\hline \multicolumn{6}{|c|}{${ }^{\mathrm{b}}$ Age group, gender, marital status, ever schooled, ethnicity, vegetable intake, and poor SRH were screened out as the confounding variables } \\
\hline \multicolumn{6}{|c|}{ 'Age group, gender, ever schooled, always lived in this village/town/city, vegetable intake, and poor SRH were screened out as the confounding variables } \\
\hline \multicolumn{6}{|c|}{$\begin{array}{l}{ }^{\mathrm{d}} \text { Age group, gender, marital status, ever schooled, always lived in this village/town/city, vegetable intake, and poor SRH were screened out as the confounding } \\
\text { variables }\end{array}$} \\
\hline
\end{tabular}

serving), vigorous fitness/leisure, and walk/bike activity might be important protective factors against poor SRH. The odds ratio of poor SRH significantly associating with vegetable intake was less than 1 , which indicated that higher vegetable intake could reduce the risk of poor SRH. Thus, Hypotheses 3 and 4 were confirmed completely.

\section{Association between levels of physical activities and poor SRH}

Supplementary Table 4a to e reported change-in-estimates for poor SRH to vigorous level of physical activity, moderate level of physical activity, walk/bike activity, vigorous fitness/leisure, and moderate fitness/leisure with potential confounding factors. In Table 5, vigorous level of physical activity was significantly associated with poor SRH (AOR $=0.79,95 \%$ CI: 0.65-0.97). Older adults with walk/bike activity and high fruit intake would face less risk of poor SRH than those without. A significant association was also observed between vigorous fitness/ leisure and poor SRH (AOR $=0.57,95 \%$ CI: 0.39-0.84). Older adults with moderate fitness/leisure had a 0.31 times higher risk of poor SRH (AOR $=0.31,95 \%$ CI: $0.26-$ 0.38 ) than those without it. In sum, these results provided support for Hypothesis 5.

\section{Discussion}

In this cross-sectional analysis, the sample was dominated by age 60 to 69 years, females, currently married status, educated level, Han majority, good health, physical inactivity, and high F\&V intake. The percentage of the respondents reported their good health status was higher than that in another study among Shanghai older adults (nearly 40\%) [59]. The empirical analyses showed that older adults with higher fruit intake had lower likelihood to perform vigorous/moderate level of physical activity, higher likelihood of performing walk/bike activity, and lower likelihood of performing vigorous/moderate fitness 
Table 3 Adjusted odds ratios (and 95\% confidence intervals) of vegetable intake (servings) and physical activity, $\mathrm{AOR}(95 \% \mathrm{Cl})$

\begin{tabular}{|c|c|c|c|c|c|}
\hline & $\begin{array}{l}\text { Vigorous level of } \\
\text { physical activity }^{\mathrm{a}}\end{array}$ & $\begin{array}{l}\text { Moderate level of } \\
\text { physical activity }^{b}\end{array}$ & Walk/bike activityc & Vigorous fitness/leisure ${ }^{d}$ & Moderate fitness/leisure ${ }^{\mathrm{e}}$ \\
\hline \multicolumn{6}{|l|}{ Vegetable intake } \\
\hline $0-4$ & 1 [Reference] & 1 [Reference] & 1 [Reference] & 1 [Reference] & 1 [Reference] \\
\hline 5 & $1.01(0.78-1.29)$ & $1.10(0.97-1.26)$ & $1.57^{* * *}(1.32-1.86)$ & $0.05^{* * *}(0.04-0.07)$ & $0.30^{* * *}(0.26-0.36)$ \\
\hline $6-9$ & $1.01(0.77-1.32)$ & $1.08(0.94-1.24)$ & $1.38^{* * *}(1.15-1.65)$ & $0.04^{* * *}(0.03-0.06)$ & $0.32^{* * *}(0.27-0.37)$ \\
\hline 10 & $1.67^{* * *}(1.30-2.13)$ & $1.51^{* * *}(1.32-1.72)$ & $1.98^{* * *}(1.65-2.37)$ & $0.05^{* * *}(0.04-0.07)$ & $0.30^{* * *}(0.25-0.35)$ \\
\hline$\geq 11$ & $3.75^{* * *}(2.89-4.87)$ & $3.14^{* * *}(2.57-3.84)$ & $1.96^{* * *}(1.54-2.49)$ & $0.01^{* * *}(0.01-0.03)$ & $0.15^{* * *}(0.12-0.20)$ \\
\hline \multicolumn{6}{|l|}{ Age group (years) } \\
\hline $60-69$ & & & & & 1 [Reference] \\
\hline$\geq 70$ & & & & & $0.42^{* * *}(0.37-0.47)$ \\
\hline \multicolumn{6}{|l|}{ Marital status } \\
\hline Never married & 1 [Reference] & & 1 [Reference] & & \\
\hline Currently married & $0.13^{* * *}(0.11-0.15)$ & & $1.19^{*}(1.00-1.42)$ & & \\
\hline Cohabiting & $0.15^{* *}(0.02-0.90)$ & & $1.03(0.27-3.98)$ & & \\
\hline Separated/divorced & $0.08^{* * *}(0.04-0.17)$ & & $1.76^{* *}(1.05-2.96)$ & & \\
\hline Widowed & $0.08^{* * *}(0.06-0.10)$ & & $0.98(0.79-1.20)$ & & \\
\hline \multicolumn{6}{|l|}{ Ever schooled } \\
\hline No & & & 1 [Reference] & & \\
\hline Yes & & & $0.95(0.83-1.08)$ & & \\
\hline \multicolumn{6}{|l|}{ Ethnicity } \\
\hline Han majority & 1 [Reference] & 1 [Reference] & 1 [Reference] & 1 [Reference] & 1 [Reference] \\
\hline Ethnic minority & $0.56(0.26-1.22)$ & $0.55^{* *}(0.33-0.92)$ & $0.70(0.40-1.20)$ & $0.11^{* * *}(0.03-0.38)$ & $0.56(0.26-1.22)$ \\
\hline \multicolumn{6}{|c|}{ Always lived in this village/town/city } \\
\hline No & & 1 [Reference] & 1 [Reference] & & \\
\hline Yes & & $0.74 * * *(0.67-0.82)$ & $0.96(0.85-1.09)$ & & \\
\hline \multicolumn{6}{|l|}{ Fruit intake } \\
\hline 0 & & & 1 [Reference] & & \\
\hline 1 & & & $1.41^{* * *}(1.15-1.74)$ & & \\
\hline 2 & & & $1.53^{* * *(1.29-1.82)}$ & & \\
\hline 3 & & & $1.33^{* * *}(1.08-1.63)$ & & \\
\hline$\geq 4$ & & & $1.25^{* *}(1.04-1.50)$ & & \\
\hline \multicolumn{6}{|l|}{ Poor SRH } \\
\hline No & & 1 [Reference] & & & \\
\hline Yes & & $1.01(0.89-1.15)$ & & & \\
\hline
\end{tabular}

Note: ${ }^{* * *},{ }^{* *}$ and $*$ indicates 1,5 and $10 \%$ significance level, respectively

AOR adjusted odds ratio

${ }^{\text {a }}$ Age group, gender, ever schooled, always lived in this village/town/city, fruit intake, and poor SRH were screened out as the confounding variables

${ }^{b}$ Age group, gender, marital status, ever schooled, and fruit intake were screened out as the confounding variables

c Age group, gender, and poor SRH were screened out as the confounding variables

${ }^{\mathrm{d}}$ Age group, gender, marital status, ever schooled, always lived in this village/town/city, fruit intake, and poor SRH were screened out as the confounding variables

e Gender, marital status, ever schooled, always lived in this village/town/city, fruit intake, and poor SRH were screened out as the confounding variables

and leisure activities. Similarly, older adults with higher vegetable intake were more likely to perform vigorous/ moderate level of physical activity and walk/bike activity and less likely to perform vigorous/moderate fitness and leisure activities. Simultaneously, high F\&V intake, vigorous level of physical activity, walk/bike activity, and vigorous/moderate fitness/leisure could reduce the risk of poor SRH. Therefore, the results provided useful insights into the role of servings of $F \& V$ intake and levels of physical activities in the health evaluations among the Chinese older adults.

The servings of $F \& V$ intake in this study appeared to be high because $>60 \%$ of the participants consumed $\geq 2$ servings of fruit and $>70 \%$ consumed $\geq 5$ servings 
Table 4 Adjusted odds ratios (and 95\% confidence intervals) of F \&V intake and poor SRH, AOR (95\%Cl)

\begin{tabular}{|c|c|c|}
\hline & Model $1^{\mathrm{a}}$ & Model $2^{b}$ \\
\hline \multicolumn{3}{|l|}{ Fruit intake } \\
\hline 0 & 1 [Reference] & \\
\hline 1 & $0.69^{* * *}(0.57-0.83)$ & \\
\hline 2 & $0.49^{* * *}(0.41-0.57)$ & \\
\hline 3 & $0.33^{* * *}(0.27-0.42)$ & \\
\hline$\geq 4$ & $0.32^{* * *}(0.27-0.38)$ & \\
\hline \multicolumn{3}{|l|}{ Vegetable intake } \\
\hline $0-4$ & & 1 [Reference] \\
\hline 5 & & $0.69^{* * *}(0.58-0.83)$ \\
\hline $6-9$ & & $0.72^{* * *}(0.59-0.87)$ \\
\hline 10 & & $0.88(0.73-1.06)$ \\
\hline$\geq 11$ & & $1.02(0.81-1.29)$ \\
\hline \multicolumn{3}{|l|}{ Marital status } \\
\hline Never married & & 1 [Reference] \\
\hline Currently married & & $0.39^{* * *}(0.34-0.45)$ \\
\hline Cohabiting & & $0.50(0.12-2.17)$ \\
\hline Separated/divorced & & $0.38^{* * *}(0.22-0.64)$ \\
\hline Widowed & & $0.56^{* * *}(0.47-0.66)$ \\
\hline \multicolumn{3}{|l|}{ Ethnicity } \\
\hline Han majority & 1 [Reference] & 1 [Reference] \\
\hline Ethnic minority & $0.69(0.40-1.20)$ & $0.84(0.50-1.43)$ \\
\hline \multicolumn{3}{|c|}{ Always lived in this village/town/city } \\
\hline No & 1 [Reference] & 1 [Reference] \\
\hline Yes & $0.93(0.82-1.05)$ & $0.88^{*}(0.77-1.00)$ \\
\hline \multicolumn{3}{|c|}{ Vigorous fitness/leisure } \\
\hline No & 1 [Reference] & 1 [Reference] \\
\hline Yes & $0.64^{* *}(0.43-0.94)$ & $0.60^{* * *}(0.41-0.87)$ \\
\hline \multicolumn{3}{|l|}{ Walk/bike activity } \\
\hline No & 1 [Reference] & \\
\hline Yes & $0.50^{* * *}(0.45-0.56)$ & \\
\hline
\end{tabular}

Note: *** ** and * indicates 1,5 and $10 \%$ significance level, respectively $A O R$ adjusted odds ratio

${ }^{\text {a } A g e ~ g r o u p, ~ g e n d e r, ~ m a r i t a l ~ s t a t u s, ~ e v e r ~ s c h o o l e d, ~ v e g e t a b l e ~ i n t a k e, ~ v i g o r o u s ~}$ level of physical activity, moderate level of physical activity, and moderate fitness/leisure were screened out as the confounding variables

${ }^{\mathrm{b}}$ Fruit intake, Age group, gender, ever schooled, vigorous level of physical activity, moderate level of physical activity, walk/bike activity, and moderate fitness/leisure were screened out as the confounding variables

of vegetables on an average day. Methodologically, outcome measures ( $\geq 2$ servings of fruit and 5 servings of vegetables per day) in this study were the same with an observational study in Australia [60], which were higher than national recommendations (fruit: $\geq 2$ servings/day and vegetables: $\geq 3$ servings/day) in African-American adults [61]. Practically, intake servings of this sample were more appropriate than those in an Australian sample which documented $32 \%$ of adults consumed $\geq 2$ servings of fruit and $30 \%$ consumed $\geq 5$ servings of vegetables as recommended by the Australian Guide to Healthy Eating [62].

Regarding associations between F\&V intake and various physical activities, the research outcome in this study was corroborated by the findings that quantitative servings of $\mathrm{F} \& \mathrm{~V}$ intake and various intensities of physical activity contributed to the health status of old age. For example, a study suggested that maintaining a healthy dietary pattern and outdoor exercises was associated with a low risk of exhibiting cognitive impairment among Chinese old adults [63]. The findings in this study was also congruent with two Chinese studies in which both socioeconomic factors [64] and physical exercise [65] were related with good SRH and a Spanish investigation showing that F\&V intake and physical activity could better SRH perception [66]. Similarly, another study indicated that diet quality and physical activity were known to influence health status [67].

Consistent with a number of early studies among older adults, this study documented the beneficial health effects of quantitative servings of F\&V intake. For example, a study among Chinese older adults in Hong Kong concluded having $\geq 3$ servings of vegetables and 2 servings of fruits daily might help prevent dementia [68]. A cross-sectional study in Tanzania found F\&V intake $(<5$ servings/day) was also associated with higher serum total cholesterol [69]. A study in Malaysia indicated inadequate $F \& V$ intake ( $<5$ servings/day) were all associated with physical inactivity [70]. Additionally, persons with frequent fruit consumers ( $\geq 4$ servings/day) had a low risk of incident metabolic syndrome in a Korean sample [71]. Another study in Southern Brazil indicated that low F\&V intake ( $\leq 4$ servings/day) was defined as an indicator of unhealthy dietary habits among older adults aged $>60$ years [72].

With respect to the role of sociodemographic factors in this study, several interesting results need explanations. Different from two prior studies in China [73, 74 ], this study convinced the role of age, ethnicity and marital status as key associating factors of the F\&V intake, physical activities, and poor SRH among the Chinese older adults. In fact, age $\geq 70$ years had significantly negative associations with moderate fitness/ leisure. This might be explained that older adults aged $\geq 70$ years tended to report worse health than the persons aged $<70$ years. Computationally, there was turning point age for SRH was at the age of 83.69 for the SRH trend on the basis of the Chinese Longitudinal Healthy Longevity Survey [75]. Additionally, ethnic minority had significantly negative associations with physical activity. Several studies in western countries also highlighted the ethnic gradient in SRH [76, 77]. Similarly, in this study, older adults with ethnic 
Table 5 Adjusted odds ratios (and 95\% confidence intervals) of physical activity and poor SRH, AOR(95\%Cl)

\begin{tabular}{|c|c|c|c|c|c|}
\hline & Model $1^{a}$ & Model $2^{b}$ & Model $3^{c}$ & Model $4^{\mathrm{d}}$ & Model $5^{e}$ \\
\hline \multicolumn{6}{|c|}{ Vigorous level of physical activity } \\
\hline No & 1 [Reference] & & & & \\
\hline Yes & $0.79^{* *}(0.65-0.97)$ & & & & \\
\hline \multicolumn{6}{|c|}{ Moderate level of physical activity } \\
\hline No & & 1 [Reference] & & & \\
\hline Yes & & $1.04(0.92-1.18)$ & & & \\
\hline \multicolumn{6}{|l|}{ Walk/bike activity } \\
\hline No & & & 1 [Reference] & & \\
\hline Yes & & & $0.53^{* * *}(0.46-0.60)$ & & \\
\hline \multicolumn{6}{|c|}{ Vigorous fitness/leisure } \\
\hline No & & & & 1 [Reference] & \\
\hline Yes & & & & $0.57^{* * *}(0.39-0.84)$ & \\
\hline \multicolumn{6}{|c|}{ Moderate fitness/leisure } \\
\hline No & & & & & 1 [Reference] \\
\hline Yes & & & & & $0.31^{* * *}(0.26-0.38)$ \\
\hline \multicolumn{6}{|l|}{ Marital status } \\
\hline Never married & 1 [Reference] & 1 [Reference] & 1 [Reference] & 1 [Reference] & \\
\hline Currently married & $0.31^{* * *}(0.29-0.34)$ & $0.31^{* * *}(0.28-0.35)$ & $0.84^{* *}(0.72-0.98)$ & $0.31^{* * *}(0.29-0.33)$ & \\
\hline Cohabiting & $0.40(0.10-1.67)$ & $0.41(0.10-1.78)$ & $1.16(0.25-5.30)$ & $0.38(0.09-1.62)$ & \\
\hline Separated/divorced & $0.29^{* * *}(0.18-0.48)$ & $0.30^{* * *}(0.18-0.49)$ & $0.74(0.43-1.25)$ & $0.30^{* * *}(0.18-0.50)$ & \\
\hline Widowed & $0.46^{* * *}(0.40-0.52)$ & $0.47^{* * *}(0.40-0.55)$ & $1.08(0.90-1.29)$ & $0.46^{* * *}(0.40-0.52)$ & \\
\hline \multicolumn{6}{|l|}{ Ethnicity } \\
\hline Han majority & 1 [Reference] & 1 [Reference] & 1 [Reference] & 1 [Reference] & 1 [Reference] \\
\hline Ethnic minority & $0.95(0.59-1.53)$ & $1.03(0.64-1.66)$ & $0.69(0.40-1.19)$ & $0.95(0.59-1.54)$ & $0.69(0.42-1.15)$ \\
\hline \multicolumn{6}{|c|}{ Always lived in this village/town/city } \\
\hline No & & 1 [Reference] & & & 1 [Reference] \\
\hline Yes & & $0.87^{* *}(0.76-0.98)$ & & & $0.37^{* * *}(0.34-0.41)$ \\
\hline \multicolumn{6}{|l|}{ Fruit intake } \\
\hline 0 & & & 1 [Reference] & & \\
\hline 1 & & & $0.71^{* * *}(0.57-0.88)$ & & \\
\hline 2 & & & $0.50^{* * *}(0.42-0.60)$ & & \\
\hline 3 & & & $0.35^{* * *}(0.27-0.44)$ & & \\
\hline$\geq 4$ & & & $0.33^{* * *}(0.27-0.40)$ & & \\
\hline
\end{tabular}

Note: ${ }^{* *}$ and ${ }^{* *}$ indicates 1 and $5 \%$ significance level, respectively

AOR adjusted odds ratio

${ }^{a}$ Fruit intake, Age group, gender, ever schooled, always lived in this village/town/city, and vegetable intake were screened out as the confounding variables

${ }^{b}$ Fruit intake, Age group, gender, ever schooled, and vegetable intake were screened out as the confounding variables

c Age group, gender, ever schooled, always lived in this village/town/city, and vegetable intake were screened out as the confounding variables

${ }^{d}$ Fruit intake, Age group, gender, ever schooled, always lived in this village/town/city, and vegetable intake were screened out as the confounding variables

${ }^{e}$ Fruit intake, Age group, gender, marital status, ever schooled, and vegetable intake were screened out as the confounding variables

minority were possibly characterized by physical activities. Simultaneously, marital status had significantly negative associations with vigorous level of physical activity and poor SRH and significantly positive associations with walk/bike activity. This could be partially explained by a study suggested that improving marital quality could be protective against functional abilities for older people [78].
Regarding physical activities associating F\&V intake, this study was consistent with the early results. For example, a cross-sectional study identified a range of sociodemographic and behavioural factors associated with F\&V intake among Chinese adults [79]. Another study convinced that physical activity and nutrition appeared to facilitate rather than hinder each other [80]. Likewise, an early study reported that F\&V intake might be too 
specific to represent an individual's overall nutritional status [81]. Similarly, a study in Brazil also reported the association between physical activity and F\&V intake [82]. Thus, the older adults with high F\&V intake might be physically active due to energy balance and healthy diet.

The benefits of physical activities and F\&V intake in the current study could be explained by a number of early studies. For example, a cross-sectional survey showed that combination of sufficient F\&V intake and adequate physical activity was significantly associated with reduced metabolic syndrome risk among adult residents of China [83]. Simultaneously, higher levels of physical activities and daily $F \& V$ intake might be protective against cognitive decline in older adults [84]. Furthermore, a study among community-dwelling older adults indicated F\&V intake could reduce a low short-term risk of frailty [85]. Another study suggested that a modest increase in F\&V intake or leisure-time physical activity could remarkably influence SRH of older adults [86].

Considering F\&V intake associating health status, this study was consistent with the early findings. For instance, higher F\&V intake was associated with a lower risk of frailty in this cohort of US women aged $\geq 60$ years [87] and a reduced risk of total mortality for Chinese adults [88]. In this study, higher F\&V intake was related to a lower likelihood of poor SRH. This might be explained by several early studies. For example, multiple studies indicated that frequent intake of F\&V was associated with the perception of better health $[89,90]$ and could reduce cardiovascular disease mortality [91] and blood triglyceride levels [92].

Regarding the physical activities associating poor SRH, this study was in line with previous studies. For example, several studies indicated physical activities were important predictors for SRH $[93,94]$. In China, physical inactivity contributed $12-19 \%$ to the risks associated with five major non-communicable diseases [95]. Similarly, another cross-sectional study concluded poor SRH status was related to a low likelihood of physical activity [96]. Likewise, another cross-sectional study concluded physical activity was a significant protective factor against metabolic syndrome in older women [97].

Furthermore, the relationship between various forms of physical activity and poor SRH could be explained by a series of health literature. For example, a mail-in survey study concluded moderate physical activity could lead to adoption of other healthy behaviors [98]. A cross-sectional study suggested that intensity of physical activity was an important contributor to neuronal function [99]. Similarly, a study in young adults suggested that vigorous level of physical activity was more closely associated with high heart rate complexity than moderate level of physical activity [100]. Additionally, multiple findings suggested that leisure-time physical activity was associated with better SRH $[101,102]$.

Notably, unhealthy eating habits are risk factors for poor health status among Chinese older adults. High salt intake is one of poor eating patterns. The sodium eating pattern is mainly characterized by pickled or salted vegetables, salted seafood, salted nuts and potato, and bacon in China. Moreover, salt added during cooking is preferred by common Chinese persons. Thus, the national average cooking salt intake exceeded recommendations of the World Health Organization $(<5 \mathrm{~g} /$ day of salt $)$ [103] and Chinese proposed intake for preventing non-communicable chronic diseases [104]. Currently, high dietary sodium intake is so difficult to control by individuals that only governmental intervention can reduce dietary sodium intake and subsequent blood pressure [105].

\section{Strength, limitations, and future directions}

There were three main strengths in this study. First, based on serving's density, fruit and vegetable intake were categorized in this study, respectively. Second, identifying and screening out confounding variables in this study was on the basis of change-in-estimate criterion. Third, the findings of tentative analysis (component loadings $>0.5$, AVE values $<0.5$, and Cronbach's alpha coefficients $<0.5)$ led to abandonment of structural equation model design.

This study had three main limitations. First, based on a survey, the assessments were all questionnaire-based and often referring only to single items, which might limit the number of the variables of interest. Besides, surveyed data of levels of physical activities and servings of $F \& V$ intake were less inaccurate than clinical diagnose data. Simultaneously, the findings here could not reflect the causal relationships among the three variables of interest. Second, the rough assessment of physical activities (10 min criteria) rather than World Health Organization recommendations for physical activity in older adults $(\geq$ 150 min of moderate-intensity aerobic physical activity (APA) or $\geq 75 \mathrm{~min}$ of vigorous-intensity APA throughout the week) was an obvious limitation of this study. Third, information about cognitive and functional status which was often considered as two important potential confounding factors was not analyzed in the present study.

Some future directions could be derived from this study. First, further studies could reanalyze the associations of interest on the basis of large sample and longitudinal data. Second, discrepancies between early outcomes in the western world and the findings in the present study could be studied further with the relevant survey datasets. Finally, mediating and moderating 
effects of servings of F\&V intake and levels of physical activities on poor SRH might be further explored.

\section{Practical implications}

F\&V intake and physical activities are the key elements of healthy ageing and important factors of modifiable risk in the prevention of poor SRH. There are several implications for health practitioners from the findings in this study. First, it was feasible to adopt servings of F\&V intake and levels of physical activities to rate and assess subjective health status. Second, health policy-designers could redesign quantities of $F \& V$ intake and exercisefriendly neighborhoods in order to promote health status among Chinese older adults. Third, in order to lead a meaningful life of successful ageing, Chinese older adults should be aware of health benefits of F\&V intake and physical activities and harmful impacts of servings, intensity, and frequency. Thus, the health policymakers should address both servings of $F \& V$ intake and levels of physical activities in cost-effective ways towards healthy Chinese older adults.

\section{Conclusion}

In conclusion, high F\&V intake, vigorous level of physical activity, walk/bike activity, and vigorous/moderate fitness/leisure were protective factors against poor SRH among Chinese older adults. As the protective lifestyle behaviors, appropriate servings of $F \& V$ intake and levels of physical activities according to individual health status should be educated, arranged, and implemented among Chinese older adults. Globally, the empirical outcomes in this study could be generalized as references for other countries. Future research is needed to initiate panel studies to address causality in the relationships among F\&V intake, physical activities, and poor SRH among Chinese older adults.

\begin{abstract}
Abbreviations
F\&V: Fruit \& vegetable; SRH: Self-rated health; SAGE-China: Study on Global Ageing and Adult Health-China; DSPs: Death Surveillance Points; PCA: Principal component analysis; AVE: Average variances extracted; AOR: Adjusted odds ratio; APA: Aerobic physical activity.
\end{abstract}

\section{Supplementary Information}

The online version contains supplementary material available at https://doi. org/10.1186/s12877-021-02709-6.

Additional file 1: Supplementary Table 1. a. Change-in-estimate for vigorous level of physical activity to fruit intake with possible confounding factors $(n=6770)$. b. Change-in-estimate for moderate level of physical activity to fruit intake with possible confounding factors $(n=6760)$. c. Change-in-estimate for walk/bike activity to fruit intake with possible confounding factors $(n=6755)$. d. Change-in-estimate for vigorous fitness/leisure to fruit intake with possible confounding factors $(n=6754)$. e. Change-in-estimate for moderate fitness/leisure to fruit intake with possible confounding factors $(n=6753)$. Supplementary Table 2 . a. Change-in-estimate for vigorous level of physical activity to vegetable intake with possible confounding factors $(n=6770)$. b. Change-in-estimate for moderate level of physical activity to vegetable intake with possible confounding factors ( $n=6760$ ). c. Change-in-estimate for walk/bike activity to vegetable intake with possible confounding factors $(n=6755)$. d. Change-in-estimate for vigorous fitness/leisure to vegetable intake with possible confounding factors $(n=6754)$. e. Change-in-estimate for moderate fitness/leisure to vegetable intake with possible confounding factors $(n=6753)$. Supplementary Table 3. a. Change-in-estimate for poor SRH to fruit intake with possible confounding factors $(n=6695)$. b. Changein-estimate for poor SRH to vegetable intake with possible confounding factors $(n=6695)$. Supplementary Table 4. a. Change-in-estimate for poor SRH to vigorous level of physical activity with possible confounding factors $(n=6770)$. b. Change-in-estimate for poor SRH to moderate level of physical activity with possible confounding factors $(n=6760)$. c. Change-in-estimate for poor SRH to walk/bike activity with possible confounding factors $(n=6755)$. d. Change-in-estimate for poor SRH to vigorous fitness/leisure with possible confounding factors $(n=6754)$. e. Change-in-estimate for poor SRH to moderate fitness/leisure with possible confounding factors $(n=6753)$.

\section{Acknowledgements}

I wish to acknowledge the very helpful comments of anonymous reviewers of the original submission.

\section{Author's contributions}

MG designed the study, performed the statistical analysis, and completed the original version. The author read and approved the final manuscript.

\section{Authors' information}

Ming Guan is head of the Family Issues Center at Xuchang University. He is interested in health care service, health change, and quality of life of migrants and elders in modern China.

\section{Funding}

This project was funded by Multi-dimensional Evaluation of Health Service System of Floating Population in Henan Province (in Chinese: 河南省流动人 口健康服务体系多维度评价研究; Project number: 2020BSH014) from 2020 Planning of Philosophy and Social Sciences in Henan Province (in Chinese: 2020年河南省哲学社会科学规划年度项目).

This project was also funded by Construction study and practice of ideological and political teaching in the course of China Geography (in Chinese: 《中国 地理》课程思政建设研究与实践; Project number: 407) from Research and Practice Project of Higher Education \& Pedagogy Reform in Henan Province in 2019 (in Chinese: 2019年度河南省高等教育教学改革研究与实践项目). The funding body played no role in the study design, data collection, data analysis, data interpretation and manuscript writing. The content is solely the responsibility of the author and does not necessarily represent the official views of the Henan Provincial Government.

\section{Availability of data and materials}

The datasets analysed during the current study were available in the WHO Multi-Country Studies Data Archive, https://apps.who.int/healthinfo/systems/ surveydata/index.php/catalog/141.

\section{Declarations}

\section{Ethics approval and consent to participate}

The data adopted was from a publicly available survey dataset whose ethical approval was obtained from the institutional review board at Shanghai Municipal Center for Disease Control \& Prevention. All methods were carried out in accordance with relevant guidelines and regulations. Written informed consent was obtained from all participants before they agreed to participate in the study. Participants were informed that they could leave the study at any time without penalty, and all personal information was kept confidential. Thus, it was not necessary to obtain ethical approval from the institutional review board at the author's institution. 


\section{Consent for publication \\ Not applicable.}

\section{Competing interests}

The author declares that he has no competing interests regarding the publication of this paper.

\section{Author details}

${ }^{1}$ Family Issues Center, Xuchang University, Road Bayi 88, Xuchang, Henan, China. ${ }^{2}$ International Issues Center, Xuchang University, Road Bayi 88, Xuchang, Henan, China. ${ }^{3}$ School of Business, Xuchang University, Road Bayi 88, Xuchang, Henan, China.

\section{Received: 3 November 2020 Accepted: 7 December 2021}

Published online: 03 January 2022

\section{References}

1. Ji T, Zhang L, Tang Z, Sun F, Li Y, Ma L. Prevalence of Normal-weight obesity in community-dwelling Chinese older adults: results from the Beijing longitudinal study of aging. Diabetes Metab Syndr Obes. 2020;13:1611-7. https://doi.org/10.2147/DMSO.S246884 PMID: 32494178; PMCID: PMC7229781.

2. Ding G, Li J, Lian Z. Both short and long sleep durations are associated with cognitive impairment among community-dwelling Chinese older adults. Medicine (Baltimore). 2020;99(13):e19667. https://doi.org/10. 1097/MD.0000000000019667 PMID: 32221096; PMCID: PMC7220266.

3. Wang Y, Ping YJ, Jin HY, Ge N, Wu C. Prevalence and health correlates of anaemia among community-dwelling Chinese older adults: the China health and retirement longitudinal study. BMJ Open. 2020;10(10):e038147. https://doi.org/10.1136/bmjopen-2020-038147 PMID: 33130563: PMCID: PMC7783604

4. Jin $\mathrm{H}$, Zhou J, Wu C. Prevalence and health correlates of reduced kidney function among community-dwelling Chinese older adults: the China health and retirement longitudinal study. BMJ Open. 2020;10(12):e042396. https://doi.org/10.1136/bmjopen-2020-042396 PMID: 33303467; PMCID: PMC7733173.

5. Lu L, Wang SB, Rao WW, Ungvari GS, Ng CH, Chiu HFK, et al. Sleep duration and patterns in Chinese older adults: a comprehensive Metaanalysis. Int J Biol Sci. 2017;13(6):682-9. https://doi.org/10.7150/ijbs. 19695 PMID: 28655994; PMCID: PMC5485624

6. Yang Y, Wang S, Chen L, Luo M, Xue L, Cui D, et al. Socioeconomic status, social capital, health risk behaviors, and health-related quality of life among Chinese older adults. Health Qual Life Outcomes. 2020;18(1):291. https://doi.org/10.1186/s12955-020-01540-8 PMID: 32859207; PMCID: PMC7456043.

7. Wang H. Survey of physical activity and health among Chinese senior citizens over 70 years old. Zhonghua Yu Fang Yi Xue Za Zhi. 2015:49(11):1005-8 Article in Chinese.

8. Gu H, Kou Y, You H, Xu X, Yang N, Liu J, et al. Measurement and decomposition of income-related inequality in self-rated health among the elderly in China. Int J Equity Health. 2019;18(1):4. https://doi.org/10. 1186/s12939-019-0909-2.

9. Chao J, Li Y, Xu H, Yu Q, Wang Y, Liu P. Health status and associated factors among the community-dwelling elderly in China. Arch Gerontol Geriatr. 2013:56(1):199-204.

10. Wu S, Wang R, Zhao Y, Ma X, Wu M, Yan X, et al. The relationship between self-rated health and objective health status: a populationbased study. BMC Public Health. 2013;13:320.

11. Zhang JP, Huang HS, Ye M, Zeng H. Factors influencing the subjective well being (SWB) in a sample of older adults in an economically depressed area of China. Arch Gerontol Geriatr. 2008;46(3):335-47.

12. Wang JR, Zhang TH. Relation between social capital factors and self-rated health among Chinese adults. Beijing Da Xue Xue Bao. 2012;44(3):392-6 (Chinese language).

13. Assari S. Cross-country differences in the additive effects of socioeconomics, health behaviors and medical comorbidities on disability among older adults with heart Disease. J Tehran Heart Cent. 2015:10(1):24-33.
14. Assari S, Lankarani MM. Does multi-morbidity mediate the effect of socioeconomics on self-rated health? Cross-country Differences. Int J Prev Med. 2015:6:85.

15. Assari S, Lankarani RM, Lankarani MM. Cross-country differences in the association between diabetes and disability. J Diabetes Metab Disord. 2014;13(1):3.

16. Assari S. Cross-country variation in additive effects of socio-economics, health behaviors, and comorbidities on subjective health of patients with diabetes. J Diabetes Metab Disord. 2014;13(1):36.

17. Elwell-Sutton TM, Jiang CQ, Zhang WS, Cheng KK, Lam TH, Leung GM, et al. Socioeconomic influences at different life stages on health in Guangzhou, China. Soc Sci Med. 2011;72(11):1884-92.

18. Méjean C, Deschamps V, Bellin-Lestienne C, Oleko A, Darmon N, Hercberg S, et al. Associations of socioeconomic factors with inadequate dietary intake in food aid users in France (the ABENA study 2004-2005). Eur J Clin Nutr. 2010;64(4):374-82.

19. Papadopoulou SK, Papadopoulou SD, Zerva A, Paraskevas GP, Dalkiranis A, loannou I, et al. Health status and socioeconomic factors as determinants of physical activity level in the elderly. Med Sci Monit. 2003:9(2):CR79-83.

20. Kahan E, Fogelman Y, Bloch B. Correlations of work, leisure, and sports physical activities and health status with socioeconomic factors: a national study in Israel. Postgrad Med J. 2005;81(954):262-5.

21. Liang J, Bennett J, Gu S. Self-reported physical health among the aged in Wuhan, China. J Cross Cult Gerontol. 1993:8(3):225-51.

22. Feng Z, Wang WW, Jones K, Li Y. An exploratory multilevel analysis of income, income inequality and self-rated health of the elderly in China. Soc Sci Med. 2012;75(12):2481-92. https://doi.org/10.1016/j.socscimed. 2012.09.028.

23. Behanova M, Reijneveld SA, Nagyova I, Katreniakova Z, van Ameijden EJC, Dijkshoorn $\mathrm{H}$, et al. Are area-level and individual-level socioeconomic factors associated with self-rated health in adult urban citizens? Evidence from Slovak and Dutch cities. Eur J Pub Health. 2017;27(suppl_2):86-92.

24. Xu J, Zhang J, Feng L, Qiu J. Self-rated health of population in Southern China: association with socio-demographic characteristics measured with multiple-item self-rated health measurement scale. BMC Public Health. 2010;10:393. Published 2010 Jul 3. https://doi.org/10.1186/ 1471-2458-10-393.

25. Yu T, Jiang Y, Gamber M, Ali G, Xu T, Sun W. Socioeconomic status and self-rated health in China: findings from a cross-sectional study. Medicine (Baltimore). 2019;98(12):e14904. https://doi.org/10.1097/MD.00000 00000014904

26. Henning-Smith C, Gonzales G. The relationship between living alone and self-rated health varies by age: evidence from the National Health Interview Survey. J Appl Gerontol. 2019;20:733464819835113. https:// doi.org/10.1177/0733464819835113.

27. Dunton GF, Cousineau M, Reynolds KD. The intersection of public policy and health behavior theory in the physical activity arena. J Phys Act Health. 2010;7(Suppl 1):S91-8. https://doi.org/10.1123/jpah.7.s1.s91 PMID: 20440019

28. Mirzaei E, Azar FEF, Ziapour A, Azadi NA, Qorbani M, Safari O, et al. The impact of educational intervention based on theory of planned behavior for promoting physical activity among middle-aged women referring to Karaj (Iran) health centers. Int Q Community Health Educ. 2021;41(4):419-26. https://doi.org/10.1177/0272684X20972849 Epub 2020 Nov 12. PMID: 33183170.

29. Sharma M, Nahar VK. Promoting physical activity in upper elementary children using multi-theory model (MTM) of health behavior change. J Prev Med Hyg. 2018;59(4):E267-76. https://doi.org/10.15167/2421 4248/jpmh2018.59.4.847 PMID: 30656229; PMCID: PMC6319127.

30. Qiao X, Ji L, Jin Y, Si H, Bian Y, Wang W, et al. Development and validation of an instrument to measure beliefs in physical activity among (pre) frail older adults: an integration of the health belief model and the theory of planned behavior. Patient Educ Couns. 2021;S0738-3991(21):00179-8. https://doi.org/10.1016/j.pec.2021.03.009 PMID: 33722429.

31. Bamford C, Heaven B, May C, Moynihan P. Implementing nutrition guidelines for older people in residential care homes: a qualitative study using normalization process theory. Implement Sci. 2012;30(7):106. https://doi.org/10.1186/1748-5908-7-106 PMID. 23110857; PMCID: PMC3514214. 
32. Thompson NR, Asare M, Millan C, Umstattd Meyer MR. Theory of planned behavior and perceived role model as predictors of nutrition and physical activity behaviors among college students in healthrelated disciplines. J Community Health. 2020;45(5):965-72. https://doi. org/10.1007/s10900-020-00814-y PMID: 32306182.

33. van der Avoort CMT, Ten Haaf DSM, de Vries JHM, et al. Higher levels of physical activity are associated with greater fruit and vegetable intake in older adults. J Nutr Health Aging. 2021;25(2):230-41. https://doi.org/ 10.1007/s12603-020-1520-3.

34. Štefan L, Petrinović L, Sporiš G, Vrgoč G. Frequency of Dietary Intake and Physical Activity in Older Adults: A Cross-Sectional Study. Nutrients. 2018;10(12):1960. Published 2018 Dec 11. https://doi.org/10.3390/ nu10121960.

35. Myint PK, Welch AA, Bingham SA, Surtees PG, Wainwright NW, Luben $\mathrm{RN}$, et al. Fruit and vegetable consumption and self-reported functional health in men and women in the European prospective investigation into Cancer-Norfolk (EPIC-Norfolk): a population-based cross-sectional study. Public Health Nutr. 2007;10(1):34-41.

36. Araújo J, Ramos E, Lopes C. Lifestyles and self-rated health, in Portuguese elderly from rural and urban areas. Acta Medica Port. 2011;24(Suppl 2):79-88.

37. Sorensen MD, Hsi RS, Chi T, Shara N, Wactawski-Wende J, Kahn AJ, et al. Women's health initiative writing group. Dietary intake of fiber, fruit and vegetables decreases the risk of incident kidney stones in women: a Women's Health Initiative report. J Urol. 2014;192(6):1694-9.

38. Michels KB, Giovannucci E, Chan AT, Singhania R, Fuchs CS, Willett WC. Fruit and vegetable consumption and colorectal adenomas in the nurses' health study. Cancer Res. 2006;66(7):3942-53.

39. Joffe $M$, Robertson A. The potential contribution of increased vegetable and fruit consumption to health gain in the European Union. Public Health Nutr. 2001:4(4):893-901.

40. Miller MG, Thangthaeng N, Poulose SM, Shukitt-Hale B. Role of fruits, nuts, and vegetables in maintaining cognitive health. Exp Gerontol. 2017:94:24-8

41. McMartin SE, Jacka FN, Colman I. The association between fruit and vegetable consumption and mental health disorders: evidence from five waves of a national survey of Canadians. Prev Med. 2013;56(3-4):225-30.

42. Liu S, Manson JE, Lee IM, Cole SR, Hennekens CH, Willett WC, et al. Fruit and vegetable intake and risk of cardiovascular disease: the Women's health study. Am J Clin Nutr. 2000;72:922-8.

43. Trachte F, Geyer S, Sperlich S. Impact of physical activity on self-rated health in older people: do the effects vary by socioeconomic status? J Public Health (Oxf). 2016;38(4):754-9.

44. Kull M. The relationships between physical activity, health status and psychological well-being of fertility-aged women. Scand J Med Sci Sports. 2002;12(4):241-7.

45. Park S, Oh SK, Seok H, Kim SK, Choi JR, Oh SS, et al. Long working hours and poor self-rated health in the young working population in Korea. J Occup Environ Med. 2019. https://doi.org/10.1097/JOM.00000000000 001606.

46. Johansson LM, Lingfors H, Golsäter M, Kristenson M, Fransson El. Can physical activity compensate for low socioeconomic status with regard to poor self-rated health and low quality-of-life? Health Qual Life Outcomes. 2019;17(1):33. https://doi.org/10.1186/s12955-019-1102-4.

47. Rocca P, Beckman A, Ekvall Hansson E, Ohlsson H. Is the association between physical activity and healthcare utilization affected by self-rated health and socio-economic factors? BMC Public Health. 2015;15:737. https://doi.org/10.1186/s12889-015-2079-5.

48. Lee HY, Kim J, Merighi JR. Physical activity and self-rated health status among older adult Cancer survivors: does intensity of activity play a role? Oncol Nurs Forum. 2015;42(6):614-24. https://doi.org/10.1188/15. ONF.614-624.

49. Ogwumike OO, Adeniyi AF, Orogbemi OO. Physical activity level of postmenopausal women in Nigeria: association with self-rated health status, overall obesity, and abdominal obesity. Women Health. 2016;56(5):487-501. https://doi.org/10.1080/03630242.2015.1101735.

50. Herman KM, Hopman WM, Sabiston CM. Physical activity, screen time and self-rated health and mental health in Canadian adolescents. Prev Med. 2015;73:112-6. https://doi.org/10.1016/j.ypmed.2015.01.030.
51. Matin N, Kelishadi R, Heshmat R, Motamed-Gorji N, Djalalinia S, Motlagh $M E$, et al. Joint association of screen time and physical activity on self-rated health and life satisfaction in children and adolescents: the CASPIAN-IV study. Int Health. 2017;9(1):58-68. https://doi.org/10.1093/ inthealth/ihw044.

52. Granger E, Williams G, Di Nardo F, Harrison A, Verma A. The relationship between physical activity and self-rated health status in European adolescents: results of the EURO-URHIS 2 survey. Eur J Pub Health. 2017;27(suppl_2):107-11. https://doi.org/10.1093/eurpub/ckw177.

53. Lachytova M, Katreniakova Z, Mikula P, Jendrichovsky M, Nagyova I. Associations between self-rated health, mental health problems and physical inactivity among urban adolescents. Eur J Pub Health. 2017;27(6):984-9. https://doi.org/10.1093/eurpub/ckx051.

54. Rhodes RE, Janssen I, Bredin SSD, Warburton DER, Bauman A. Physical activity: health impact, prevalence, correlates and interventions. Psychol Health. 2017;32(8):942-75.

55. Mehmetoglu M. "CONDISC: Stata module to perform convergent and discriminant validity assessment in CFA," statistical software components S458003, Boston College Department of Economics; 2015.

56. Fornell C, Larcker DF. Evaluating structural equation models with unobservable variables and measurement error. J Mark Res. 1981;18(1):39-50.

57. Lee PH. Is a cutoff of $10 \%$ appropriate for the change-in-estimate criterion of confounder identification? J Epidemiol. 2014;24:161-7. https:// doi.org/10.2188/jea.JE20130062.

58. Wang Z. "CONFND: Stata module to plot and display estimates to assess confounding," statistical software components S456757, Boston College Department of Economics; 2006.

59. Dong W, Wan J, Xu Y, Chen C, Bai G, Fang L, et al. Determinants of selfrated health among shanghai elders: a cross-sectional study. BMC Public Health. 2017;17(1):807. https://doi.org/10.1186/s12889-017-4718-5.

60. Tran B, Falster MO, Douglas K, Blyth F, Jorm LR. Health behaviours and potentially preventable hospitalisation: a prospective study of older Australian adults. PLoS One. 2014;9(4):e93111. Published 2014 Apr 1. https://doi.org/10.1371/journal.pone.0093111.

61. Gary TL, Baptiste-Roberts K, Gregg EW, et al. Fruit, vegetable and fat intake in a population-based sample of African Americans. J Natl Med Assoc. 2004;96(12):1599-605.

62. Magarey A, McKean S, Daniels L. Evaluation of fruit and vegetable intakes of Australian adults: the National Nutrition Survey 1995. Aust N Z J Public Health. 2006;30(1):32-7. https://doi.org/10.1111/j.1467-842x. 2006.tb00083.x.

63. Wang Z, Pang Y, Liu J, Wang J, Xie Z, Huang T. Association of healthy lifestyle with cognitive function among Chinese older adults. Eur J Clin Nutr. 2020. https://doi.org/10.1038/s41430-020-00785-2 PMID: 33116235.

64. Cai J, Coyte PC, Zhao H. Determinants of and socio-economic disparities in self-rated health in China. Int J Equity Health. 2017;16(1):7. https://doi.org/10.1186/s12939-016-0496-4.

65. Chen H, Liu Y, Zhu Z, Li Z. Does where you live matter to your health? Investigating factors that influence the self-rated health of urban and rural Chinese residents: evidence drawn from Chinese general social survey data. Health Qual Life Outcomes. 2017;15(1):78. https://doi.org/ 10.1186/s12955-017-0658-0.

66. Sayón-Orea C, Santiago S, Bes-Rastrollo M, Martínez-González MA, Pastor MR, Moreno-Aliaga MJ, et al. Determinants of Self-Rated Health Perception in a Sample of a Physically Active Population: PLENUFAR VI Study. Int J Environ Res Public Health. 2018;15(10):E2104. https://doi. org/10.3390/ijerph15102104.

67. Oftedal S, Kolt GS, Holliday EG, Stamatakis E, Vandelanotte C, Brown WJ, et al. Associations of health-behavior patterns, mental health and selfrated health. Prev Med. 2019;118:295-303. https://doi.org/10.1016/j. ypmed.2018.11.017.

68. Lee ATC, Richards M, Chan WC, Chiu HFK, Lee RSY, Lam LCW. Lower risk of incident dementia among Chinese older adults having three servings of vegetables and two servings of fruits a day. Age Ageing. 2017;46(5):773-9. https://doi.org/10.1093/ageing/afx018.

69. Kakarmath SS, Zack RM, Leyna GH, et al. Dietary determinants of serum total cholesterol among middle-aged and older adults: a populationbased cross-sectional study in Dar es Salaam, Tanzania. BMJ Open. 2017;7(5):e015028. Published 2017 Jun 6. https://doi.org/10.1136/ bmjopen-2016-015028. 
70. Chan YY, Sooryanarayana R, Mohamad Kasim N, et al. Prevalence and correlates of physical inactivity among older adults in Malaysia: findings from the National Health and morbidity survey (NHMS) 2015. Arch Gerontol Geriatr. 2019;81:74-83. https://doi.org/10.1016/j.archg er.2018.11.012.

71. Lim M, Kim J. Association between fruit and vegetable consumption and risk of metabolic syndrome determined using the Korean genome and epidemiology study (KoGES). Eur J Nutr. 2020;59(4):1667-78. https://doi.org/10.1007/s00394-019-02021-5.

72. França VF, Barbosa AR, D'Orsi E. Cognition and indicators of dietary habits in older adults from southern Brazil. PLoS One. 2016;11(2):e0147820. Published 2016 Feb 19. https://doi.org/10. 1371/journal.pone.0147820.

73. Liu F, Zhang C, Liang Y, Deng Q, Hang D, Pan Y, et al. Epidemiology of self-rated health in rural China: a population-based crosssectional study. Sci Rep. 2017;7(1):4459. https://doi.org/10.1038/ s41598-017-04381-6.

74. Xie Z, Poon AN, Wu Z, Jian W, Chan KY. Is occupation a good predictor of self-rated health in China? PLoS One. 2015;10(5):e0125274. https://doi.org/10.1371/journal.pone.0125274 eCollection 2015.

75. Li G, Hou G, Xie G, Yang D, Jian H, Wang W. Trajectories of self-rated health of Chinese elders: a piecewise growth model analysis. Front Psychol. 2019;10:583. https://doi.org/10.3389/fpsyg.2019.00583 eCollection 2019.

76. Shaw RJ, Pickett KE. The association between ethnic density and poor self-rated health among US black and Hispanic people. Ethn Health. 2011;16(3):225-44. https://doi.org/10.1080/13557858.2011.561428.

77. Thayer ZM, Kuzawa CW. Ethnic discrimination predicts poor self-rated health and cortisol in pregnancy: insights from New Zealand. Soc Sci Med. 2015;128:36-42. https://doi.org/10.1016/j.socscimed.2015.01. 003 Epub 2015 Jan 6.

78. Gyasi RM, Phillips DR. Gender, self-rated health and functional decline among community-dwelling older adults. Arch Gerontol Geriatr. 2018;77:174-83. https://doi.org/10.1016/j.archger.2018.05.010.

79. Li L, Ouyang Y, Wang H, Huang F, Wang Y, Zhang J, et al. Disparities in fresh fruit and vegetable intake by sociodemographic and behavioural factors among adults in China. Public Health Nutr. 2020;14:1-8. https://doi.org/10.1017/S1368980020003274 PMID: 32924898.

80. Fleig L, Küper C, Lippke S, Schwarzer R, Wiedemann AU. Cross-behavior associations and multiple health behavior change: a longitudinal study on physical activity and fruit and vegetable intake. J Health Psychol. 2015;20(5):525-34.

81. Chai W, Nigg CR, Pagano IS, Motl RW, Horwath C, Dishman RK. Associations of quality of life with physical activity, fruit and vegetable consumption, and physical inactivity in a free living, multiethnic population in Hawaii: a longitudinal study. Int J Behav Nutr Phys Act. 2010;7:83.

82. Ward J, Friche AA, Caiaffa WT, Proietti FA, Xavier CC, Roux AV. Association of socioeconomic factors with body mass index, obesity, physical activity, and dietary factors in Belo Horizonte, Minas Gerais state, Brazil: the BH health study. Cad Saude Publica. 2015;31(Suppl 1):182-94.

83. Li XT, Liao W, Yu HJ, et al. Combined effects of fruit and vegetables intake and physical activity on the risk of metabolic syndrome among Chinese adults. PLoS One. 2017;12(11):e0188533. Published 2017 Nov 21. https://doi.org/10.1371/journal.pone.0188533.

84. Cohen A, Ardern Cl, Baker J. Physical activity mediates the relationship between fruit and vegetable consumption and cognitive functioning: a cross-sectional analysis. J Public Health (Oxf). 2017;39(4):e161-9. https://doi.org/10.1093/pubmed/fdw113.

85. García-Esquinas E, Rahi B, Peres K, et al. Consumption of fruit and vegetables and risk of frailty: a dose-response analysis of 3 prospective cohorts of community-dwelling older adults. Am J Clin Nutr. 2016;104(1):132-42. https://doi.org/10.3945/ajcn.115.125781.

86. Södergren M, McNaughton SA, Salmon J, Ball K, Crawford DA. Associations between fruit and vegetable intake, leisure-time physical activity, sitting time and self-rated health among older adults: crosssectional data from the WELL study. BMC Public Health. 2012;12:551. Published 2012 Jul 25. https://doi.org/10.1186/1471-2458-12-551.

87. Fung TT, Struijk EA, Rodriguez-Artalejo F, Willett WC, Lopez-Garcia E. Fruit and vegetable intake and risk of frailty in women 60 years old or older. Am J Clin Nutr. 2020;112(6):1540-6. https://doi.org/10.1093/ ajcn/nqaa256 PMID: 33022693; PMCID: PMC7727483.

88. GuY, He Y, Ali SH, Harper K, Dong H, Gittelsohn J. Fruit and vegetable Intake and all-cause mortality in a Chinese population: the China health and nutrition survey. Int J Environ Res Public Health. 2021;18(1):342. https://doi.org/10.3390/ijerph18010342 PMID: 33466375; PMCID: PMC7794965.

89. Steptoe A, Perkins-Porras L, Hilton S, Rink E, Cappuccio FP. Quality of life and self-rated health in relation to changes in fruit and vegetable intake and in plasma vitamins $C$ and $E$ in a randomised trial of behavioural and nutritional education counselling. $\mathrm{Br} J$ Nutr. 2004;92(1):177-84.

90. Lengyel CO, Tate RB, Obirek Blatz AK. The relationships between food group consumption, self-rated health, and life satisfaction of community-dwelling Canadian older men: the Manitoba follow-up study. J Nutr Elder. 2009;28(2):158-73.

91. Stefler D, Pikhart $H$, Kubinova R, Pajak A, Stepaniak U, Malyutina $S$, et al. Fruit and vegetable consumption and mortality in Eastern Europe: Longitudinal results from the Health,Alcohol and Psychosocial Factors in Eastern Europe study. Eur J Prev Cardiol. 2016;23(5):493-501.

92. Yuan C, Lee HJ, Shin HJ, Stampfer MJ, Cho E. Fruit and vegetable consumption and hypertriglyceridemia: Korean National Health and nutrition examination surveys (KNHANES) 2007-2009. Eur J Clin Nutr. 2015;69(11):1193-9.

93. Hosseinkhani Z, Hassanabadi HR, Parsaeian M, Nedjat S, Foroozanfar Z. The role of mental health, academic stress, academic achievement, and physical activity on self-rated health among adolescents in Iran: a multilevel analysis. J Educ Health Promot. 2020;28(9):182. https://doi.org/10.4103/jehp.jehp_161_20 PMID: 33015205; PMCID: PMC7497124.

94. Yaya S, Bishwajit G. Patterns of physical activity and self-rated health among adult populations in South Asia. Cent Asian J Glob Health. 2020;9(1):e347. https://doi.org/10.5195/cajgh.2020.347 PMID: 33062399; PMCID: PMC7538877.

95. Zhang J, Chaaban J. The economic cost of physical inactivity in China. Prev Med. 2013;56(1):75-8.

96. Cimarras-Otal C, Calderón-Larrañaga A, Poblador-Plou B, GonzálezRubio F, Gimeno-Feliu LA, Arjol-Serrano JL, et al. Association between physical activity, multimorbidity, self-rated health and functional limitation in the Spanish population. BMC Public Health. 2014;14:1170. https://doi.org/10.1186/1471-2458-14-1170.

97. Lin $\mathrm{CH}$, Chiang SL, Yates P, et al. Moderate physical activity level as a protective factor against metabolic syndrome in middle-aged and older women. J Clin Nurs. 2015;24(9-10):1234-45. https://doi.org/10. $1111 /$ jocn.12683.

98. Blakely F, Dunnagan T, Haynes G, Moore S, Pelican S. Moderate physical activity and its relationship to select measures of a healthy diet. J Rural Health. 2004;20(2):160-5. https://doi.org/10.1111/j.1748-0361. 2004.tb00023.x.

99. Dougherty RJ, Schultz SA, Kirby TK, et al. Moderate physical activity is associated with cerebral glucose metabolism in adults at risk for Alzheimer's disease. J Alzheimers Dis. 2017;58(4):1089-97. https://doi. org/10.3233/JAD-161067.

100. Soares-Miranda L, Sandercock G, Vale S, et al. Benefits of achieving vigorous as well as moderate physical activity recommendations: evidence from heart rate complexity and cardiac vagal modulation. J Sports Sci. 2011;29(10):1011-8. https://doi.org/10.1080/02640414. 2011.568513.

101. Sperlich S, Beller J, Epping J, Tetzlaff J, Geyer S. Trends in self-rated health among the elderly population in Germany from 1995 to 2015 - the influence of temporal change in leisure time physical activity. BMC Public Health. 2020;20(1):113. https://doi.org/10.1186/s12889020-8218-7 PMID: 31992257; PMCID: PMC6988275.

102. Kim Y, Schneider T, Faß E, Lochbaum M. Personal social capital and self-rated health among middle-aged and older adults: a crosssectional study exploring the roles of leisure-time physical activity and socioeconomic status. BMC Public Health. 2021;21(1):48. https:// doi.org/10.1186/s12889-020-10043-6 PMID: 33407300; PMCID: PMC7789776. 
103. Zhang J, Wang H, Wang Z, et al. Trends in adult cooking salt Intake China, 1991-2018. China CDC Wkly. 2020;2(7):104-8.

104. Fang K, He Y, Fang Y, Lian Y. Dietary Sodium Intake and Food Sources Among Chinese Adults: Data from the CNNHS 2010-2012. Nutrients. 2020;12(2):453. https://doi.org/10.3390/nu12020453 Published 2020 Feb 11.

105. Xu A, Ma J, Guo X, et al. Association of a province-wide intervention with salt Intake and hypertension in Shandong Province, China, 2011-2016. JAMA Intern Med. 2020;180(6):877-86. https://doi.org/10. 1001/jamainternmed.2020.0904.

\section{Publisher's Note}

Springer Nature remains neutral with regard to jurisdictional claims in published maps and institutional affiliations.

- fast, convenient online submission

- thorough peer review by experienced researchers in your field

- rapid publication on acceptance

- support for research data, including large and complex data types

- gold Open Access which fosters wider collaboration and increased citations

- maximum visibility for your research: over $100 \mathrm{M}$ website views per year

At BMC, research is always in progress.

Learn more biomedcentral.com/submissions 